\title{
La Expansión Internacional de las Empresas
}

\author{
Martha de Jesús Guerrero Guzmán ${ }^{1}$ \\ Alicia Cristina Silva Calpa ${ }^{2}$ \\ Martha Lucía Fuertes $D .^{3}$
}

\section{Resumen}

El proceso de globalización de la economía mundial ha generado que cada vez mayor cantidad de empresas deseen expandir sus negocios a territorios internacionales. Frente a esta situación los directivos y gerentes deben desarrollar acciones antes y durante su expansión para poder salir avante en ese mercado competido y polémico. Este escrito pretende dar respuesta a la pregunta: ¿qué aspectos debe tener en cuenta una empresa si desea expandirse internacionalmente?.

Se analizan los diversos aspectos que las empresas deben analizar antes y después de sus procesos de internacionalización, los cuales se pretenden asumir con nuevos enfoques de expansión e innovación, para lograr otros niveles de competitividad global. Los retos nos solamente se limitan a las estrategias financieras y productivas, sino también hacia la comprensión de la dinámica internacional, para lograr en materia de gestión, ventajas y aliados estratégicos.

\section{Palabras Clave:}

\footnotetext{
${ }^{1}$ Administradora de Empresas, Especialista en Pedagogía, Mg en Administración de Empresas y Liderazgo Estratégico. Estudiante de Doctorado en Administración.

${ }^{2}$ Administradora de Empresas, Especialista en Pedagogía, Mg en Sistemas de Calidad y Productividad. Estudiante de Doctorado en Administración.

${ }^{3}$ Contadora Pública, Especialista en Finanzas, Maestría en Administración, docente Universidad Nacional Abierta y a Distancia - UNAD. martha.fuertes@unad.edu.co
} 
Expansión Internacional, Ventaja Competitiva, Gestión internacional, Alianzas Estratégicas

\section{Introducción:}

En primera instancia ser realiza una revisión bibliográfica sobre el tema en estudio y luego se generan conclusiones en torno a la revisión, y se da respuesta a la pregunta formulada.

La metodología utilizada se basa en la revisión de diferentes fuentes bibliográficas de información sobre los temas estudiados en el curso Manangin in a world-wide context.

\section{Revisión Bibliográfica}

\section{Expansión en el extranjero}

Los negocios internacionales cada vez toman mayor auge dentro del contexto mundial de los negocios debido a la globalización, y al interés de las empresas de expandirse en territorios extranjeros. Daniels (2004) relaciona 3 objetivos de operación importantes que pueden inducir a las empresas a participar en negocios internacionales: Expandir las ventas Adquirir recursos y Minimizar el riesgo.

Expandir las ventas: En el mundo hay mayor cantidad de posibles consumidores y clientes para los productos, por lo cual las empresas pueden aumentar su mercado potencial y objetivo al incursionar en mercados extranjeros. En esa misma línea la expansión global genera a las compañías mayor rentabilidad. Como ejemplo de esta situación están las empresas Sony de Japón, Nestlé de Suiza, y Michelin de Francia, entre otros.

Adquirir recursos: una empresa puede operar en el extranjero para adquirir insumos, capital o tecnología que no hay en su país de origen, o que se consiga a menor costo, o que pueda servir para mejorar la calidad de sus productos o servicios. Por ejemplo, Avon por 
medio de su estrategia de marketing desarrollada en Latinoamérica, decidió utilizarla para penetrar en el mercado de Estados Unidos.

Minimizar el riesgo: Para minimizar las fluctuaciones de las ventas, las empresas aprovechan las diferencias de los ciclos económicos en diferentes países (recesiones y expansiones). Por ejemplo, en el 2001 Nestlé tuvo un crecimiento más lento en Europa Occidental y Estados Unidos, que compensa con un crecimiento mayor en Asia, Europa Oriental y América Latina.

\section{Estrategias multinacionales}

Según Cárdenas (2007), “La globalización también implica riesgos y amenazas. Las economías abiertas se hacen más dependientes del resto del mundo y, por esta razón, los acontecimientos externos pueden afectarles de manera significativa”. En ese sentido, al decidir ingresar en mercados internacionales, las empresas deben prepararse en cómo hacerlo. Es por ello que realizan el estudio del entorno internacional, y desarrollan estrategias de marketing. El estudio del entorno involucra los factores macroambientales como el cultural, el político, el legal, el económico, el demográfico.

Frente a esta situación, Daniels, Radebaugh, y Sullivan (2004), enuncian: "Los negocios deben enfrentar ambientes políticos y legales. El proceso político implica las aportaciones de diversos grupos de interés, la expresión de intereses que afectan la formulación de políticas, la suma de esos intereses a las alternativas clave, el desarrollo de políticas, y la implantación y adjudicación de las políticas".

El aspecto demográfico es importante porque las personas constituyen el mercado, es esencial identificar el nivel de ingresos para determinar si son clientes viables y cuál es su nivel de consumo. Todas las características demográficas que permitan lograr estructuras de 
nuevas segmentación de los mercados a nivel internacionales, las cuales fluctúan debido a los cambios constantes del entorno global.

El sistema económico del país también debe ser estudiado por cuanto de esto depende saber quien controla las actividades de producción y distribución. El factor económico integra entre otros aspectos, los precios, los indicadores de producción, el PIB, rendimientos en bolsas de valores.

Para Cárdenas (2007), “ningún gerente puede permitirse ignorar las políticas y regulaciones del país en el cual realiza actividades de marketing internacional. Sin importar el lugar donde se ubiquen, las empresas siempre serán afectadas por las políticas gubernamentales y el sistema jurídico".

El aspecto cultural es un tema de especial relevancia por cuanto requiere conocer y entender diferentes tipos de comportamientos, de creencias, diversidad de gustos, necesidades y motivaciones de la gente de los lugares extranjeros. Según Daniels (2004) "la cultura consiste en normas específicas aprendidas, basadas en actitudes, valores y creencias que existen en toda nación. Para el mismo autor "las áreas problemáticas que pueden dificultar la conciencia cultural de los gerentes son: las reacciones subconscientes a las circunstancias, y la suposición de que todos los subgrupos sociales son similares” (p. 47).

En ese sentido la compañía enfrentará a problemas que genera la heterogeneidad cultural de los clientes, competidores, proveedores, colaboradores. Por lo cual debe desarrollar acciones para adaptarse a las nuevas culturas y a la vez preservar su identidad.

Frente a esta situación Rodal y Salamanca (2005), afirman que los directivos deberán manejar dos fuerzas opuestas: "una fuerza que tiende hacia la diferenciación cultural para 
lograr adaptarse a las características culturales específicas del nuevo ambiente de negocios; y otra fuerza que tiende hacia la integración cultural de la empresa para preservar su identidad colectiva".

La importancia de realizar el análisis del entorno internacional facilita a las empresas conocer y familiarizarse con las prácticas culturales y comerciales del país en el cual desea incursionar. El desarrollo de estrategias de internacionalización explica que Bimbo participe de los volúmenes importantes de ventas de cada una de sus marcas.

\section{Ventaja competitiva}

La competitividad que exige la globalización, exige a las compañías internacionales para permanecer en los mercados extranjeros crear diferencias y ventajas frente a sus competidores. Para Bradley y Calderón (2006), La competitividad es "la capacidad inmediata y futura, y la oportunidad de las empresas para diseñar, fabricar y comercializar productos en sus entornos respectivos cuyas características, conforman un paquete más atractivo que el de los competidores de mercados nacionales o extranjeros".

En la actualidad la tecnología y el conocimiento facilitan a las empresas la creación e innovación de valores agregados a sus productos para permitir el ingreso en nuevos mercados.

Al respecto Bradley y Calderón (2006) afirman que "cuanto mayor es el conocimiento y la intensidad tecnológica de los productos de la empresa, más posibilidades tendrá de diferenciarse en los mercados internacionales". Con una ventaja competitiva las compañías logran mayores beneficios para consumidores y para la empresa generando mayores ingresos, logrando posicionamiento y permanencia de largo plazo en el mercado internacional.

\section{Responsabilidad social, ética y moral}


La responsabilidad social y ambiental es importante no solamente por cumplir con las normas ambientales del país, sino porque las empresas deben proyectar una imagen de responsabilidad y ética frente al nuevo mercado. Una empresa que no disponga de normas ambientales muy seguramente se verá afectada con consumidores transitorios, y se presenta poco atractiva para mano de obra calificada.

Según Riccardi (2004) con la responsabilidad social, las empresas deben ser capaces de incorporar un sistema de ética y valores que permee a todo su contexto, que sean de aplicación continua y permanente, que satisfagan las necesidades de la comunidad, sin afectar el medio ambiente.

Las compañías internacionales con prácticas de responsabilidad social y respeto por el medio ambiente, generan una imagen positiva y de confianza frente a la comunidad local, lo que abre las posibilidades para cautivar el mercado.

\section{Gestión internacional}

De acuerdo con Bartlett, Ghoshal \& Birkinshaw (2004), "el papel o rol del "gerente general" se hace más difícil a medida que las empresas multinacionales se mueven a estructuras dominadas por unidades de negocios globales y clientes globales. En tales situaciones, el gerente del país frecuentemente es responsable por los resultados, aun cuando sólo tenga limitada autoridad formal sobre las personas y los activos dentro de su jurisdicción".

Igualmente, Bartlett et al., (2004) amplían el rol o las tres tareas vitales que el gerente de país debe jugar: ahora no sólo era un sensor sino que tenía que actuar como un intérprete bicultural; ser el jefe avocado y defensor de las necesidades nacionales, y la responsabilidad como implementador activo de la estrategia de la empresa. 
Influye en gran parte la trayectoria nacional de la compañía, así como también su estructura organizacional, los estilos de dirección, las estrategias de marketing internacional, entre otros.

Otro aspecto importante a contemplar es el administrar personal internacional. Para Rodríguez (2007) hay varios factores que diferencian la administración de personal nacional de la internacional: "Diferentes mercados de trabajo, problemas de movilidad internacional, estilos y prácticas administrativas nacionales, orientaciones nacionales, estrategia y control”.

\section{Alianzas Estratégicas}

Para Czinkota y Ronkainen (2008), "las alianzas estratégicas son redes de empresas las cuales colaboran para el logro de un determinado proyecto u objetivo". Para el mismo autor "las alianzas pueden variar de la cooperación informativa en el área de desarrollo de mercados, hasta la propiedad conjunta de operaciones mundiales”. Por ejemplo, Texas Instruments ha reportado acuerdos con empresas como IBM, Hyundai, y Alcatel.

De acuerdo a Bradley y Calderón (2006), entre los requisitos para una alianza estratégica están:

- Conocimiento producto - mercado

- Acceso a mercados y a la distribución

- Know-how de procesos y productos

- Capacidad productiva

- Recursos de gestión exclusivos

Las alianzas estratégicas facilitan el acceso a los nuevos mercados, minimizan esfuerzos de producción y permiten compartir los riesgos, inclusive para enfrentar la competencia.

\section{Conclusiones}


Como conclusión se dará respuesta a la pregunta sobre: ¿qué aspectos debe tener en cuenta una empresa cuando desea expandirse internacionalmente?. Es necesario realizar un análisis del entorno internacional para conocer las condiciones del país extranjero, potencializar las fortalezas de la compañía y aprovechar las oportunidades, por medio de realizar una planeación estratégica que involucre acciones para enfrentar la diversidad cultural de sus Stakehlders sin perder su identidad. Entre más una compañía crezca internacionalmente deberá enfrentar problemas complejos, por eso debe realizar la investigación de la situación económica del país para tomar acertadas decisiones. El análisis de los indicadores económicos de cada país depende del proyecto que se desea desarrollar.

Cada empresa deberá realizar un estudio exhaustivo de las diferentes variables, actores, barreras de entrada, riesgos, y demás elementos que afecten su desarrollo en el extranjero, con el fin de tomar la decisión de expandir vertical u horizontalmente. También requiere estudiar la ubicación geográfica y la localización. Además, en el mundo globalizado actual, el mercado internacional está conformado por empresas cada vez más competitivas. En ese sentido, se siente la necesidad de dirigir esfuerzos a lograr una ventaja competitiva que garantice la supervivencia en un mercado cada vez más competido. De aquí se desprende la importancia de la generación de valor para lograr la diferencia con la competencia.

La globalización brinda a las compañías la posibilidad de la expansión territorial, sin embargo, también implica riesgos y desafíos para las empresas y personas que desean expandir sus negocios internacionalmente. Una forma de reducir algunos riesgos de entrada a un nuevo mercado en el plano internacional es por medio de las alianzas estratégicas. Estas alianzas o acuerdo de colaboración, permiten además minimizar costos y lograr beneficios tributarios. 
Las alianzas también pueden generar una fuerte ventaja competitiva, por lo cual es una herramienta que las empresas podrían utilizar para lograr sus objetivos de expansión en el extranjero. Finalmente, la expansión internacional requiere contar con directores y líderes capacitados, con experiencia, innovación y creatividad para sortear las situaciones de cambio, $\mathrm{y}$, para consolidar y guiar un equipo de trabajo en pro de satisfacer las necesidades de los consumidores en mercados internacionales, que asegure la permanencia a largo plazo.

Un ejemplo de una empresa que ha tenido resultados positivos en su expansión a países extranjeros gracias a su gestión internacional es el Grupo Bimbo, que fue fundado en México en 1945 y hoy es una de las empresas de panificación más importantes del mundo por su posicionamiento en diversos mercados y por sus volúmenes de producción y ventas que lo convierten en un líder indiscutible de su ramo en México y Latinoamérica. Con presencia en 14 países de América y Europa, cuenta con más de 4.500 productos y con más de 100 marcas de prestigio. El desarrollo de estrategias de internacionalización explica que Bimbo participe de los volúmenes importantes de ventas de cada una de sus marcas.

\section{Referencias Bibliográficas}

Bartlett, C., Goshal, S. \& Birkinshaw, J. (2004). Gestión Transnacional. New York.Mc Graw Hill, p. 47

Bradley, Frank y Calderón, Haydeé (2006). Marketing Internacional. Editorial Pearson. España, p.p 43,76

Cárdenas, M. (2007). Introducción a la Economía Colombiana. Colombia. Editorial Alfaomega, p. 122

Czinkota, M. y Ronkainen, L.A. (2008). Marketing Internacional. Mèxico. Cengage, p.127, 301 
Daniels, J. (2004). Negocios Internacionales. Editorial Pearson. México, p.p 5, 6

Rodal Arciniega, José Luis Agustín. Salamanca Pacheco, Elizabeth (2005). Perspectivas de la administración internacional. México. Cengage Learning Editores, p. 11

Riccardo, R., (2004) La Responsabilidad Social. Revista Ibero Americana de Estrategia. Volumen 3. P 115

Rodríguez V.J. (2007). Un Modelo de Administración de Personal Internacional. Cengage Learning México, p. 658 